
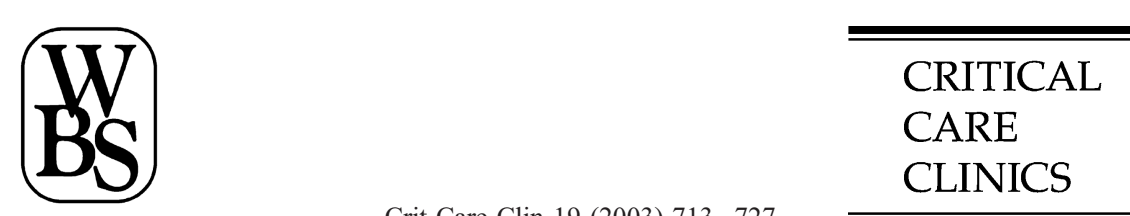

Crit Care Clin 19 (2003) 713-727

\title{
Chronic obstructive pulmonary disease in geriatric critical care
}

\author{
John E. Heffner, MD, FCCP, FCP*, Kristin B. Highland, MD \\ Pulmonary Divison, 812 CSB, Medical University of South Carolina, 96 Jonathan Lucas Street, \\ P.O. Box 250623, Charleston, SC 29425, USA
}

The term "chronic obstructive pulmonary disease" (COPD) describes a category of respiratory conditions characterized by inflammatory damage to small and large airways, destruction of lung parenchyma, and limitation of expiratory airflow. Smoking is the primary etiologic factor for most patients with COPD, who present with clinical manifestations of chronic bronchitis, emphysema, or a combination of these two disorders. Chronic bronchitis is defined by the presence of chronic cough in patients who experience airway mucus hypersecretion, increased risk of bronchial infections, and expiratory airflow limitation. Emphysema denotes the presence of irreversible lung damage with destruction of alveolar tissue that causes impaired respiratory gas exchange and expiratory airway collapse with airflow limitation.

The prevalence and societal impact of COPD have increased over the last several decades. It is estimated using American Thoracic Society definition of COPD that 16 million people in the United States have symptomatic COPD [1], which now accounts for $4 \%$ of all deaths in this country [2] making it the fourth leading cause of death. In 1999, 60,222 men and 57,692 women died with a diagnosis of COPD [3]. Application of less restrictive definitions of COPD by the Global Initiative for Chronic Obstructive Lung Disease increases the estimate of the number of persons in the United States with COPD to 24.2 million adults (14.3\% of the population) [3]. An estimated 2.4 million of these adults have moderate to severe COPD by the Global Initiative for Chronic Obstructive Lung Disease criteria with an $\mathrm{FEV}_{1}$ less than $50 \%$ of predicted. Although age-adjusted death rates for stroke and coronary artery disease have declined over the last 30 years, the death rate for COPD has increased by $70 \%$ (age-adjusted death rate of 21.1/100,000 persons) [4]. The direct medical costs of COPD are estimated to be $\$ 18$ billion a year in the United States in 2002 dollars [5]. COPD has a major

\footnotetext{
* Corresponding author.

E-mail address: heffnerj@musc.edu (J.E. Heffner).
} 
worldwide impact, Predicted to become the fifth leading burden to world health by 2020 [6]. COPD now causes 3 million deaths worldwide each year [7].

The elderly are especially subject to the health effects of COPD. COPD is the primary or contributing diagnosis for more than $18 \%$ of hospitalizations of patients $\geq 65$ years of age [3]. Medicare health care expenditures are 2.5 times higher for elderly patients with COPD compared with age-matched persons without this condition $(\$ 8,482$ versus $\$ 3,511)$ [8]. The mean per-person direct medical expenditures among persons with COPD $\geq 40$ years of age is $\$ 6,469$ in 1987 dollars [9]. Results from two large epidemiologic studies-the third National Health and Nutrition Examination Survey and the Estudio Epidemiolólico de la EPOC en España Survey - note the highest COPD occurrence rates in the elderly $[10,11]$. Between $30 \%$ to $43 \%$ of current smokers in older age groups were noted to have symptomatic COPD in these large population-based surveys $[10,11]$. Because of recent trends in smoking habits, the prevalence of COPD is higher in women than in men.

The prevalence and societal impact of COPD are predicted to increase. Feenstra et al [12] projected with a dynamic life-table model that loss of life years due to COPD in The Netherlands will increase by 60\% in 2015 compared with the baseline year of 1994 . Health care costs due to COPD are predicted to increase by $90 \%$ over the same 19 -year period.

\section{Acute exacerbations of airway disease}

Elderly patients with moderate to severe COPD experience acute exacerbations of their airway disease, each of which presents a risk for acute respiratory failure. Although definitions of acute exacerbations vary, recent consensus statements define exacerbations by the presence of one or more of the cardinal symptoms of increased dyspnea, increased sputum volume, and increased sputum purulence [13]. Using this definition, the severity of acute exacerbations is graded by the Winnepeg criteria (Box 1) [14].

An international working group of pulmonary physicians has recommended a more comprehensive definition of acute exacerbations. This group contends that the requirement for symptoms of bronchitis (cough and purulent sputum) underidentifies patients with acute exacerbations. Their proposed definition of an exacerbation is "a sustained worsening of the patient's condition, from the stable state and beyond normal day-to-day variations, that is acute in onset and necessitates a change in regular medication in a patient with underlying COPD" [15]. The severity of acute exacerbations using this definition are graded by the level of health care used (see Box 1) [15].

Regardless of the definition used, elderly patients with advanced COPD experience on average two to three acute exacerbations each year, with each episode lasting 12 days [16]. The pathophysiology of acute exacerbations of COPD is incompletely understood, but increased concentrations of proinflammatory mediators and inflammatory cells in expectorated sputum, broncho- 


\section{Box 1. Criteria for grading the severity of an acute exacerbation of chronic bronchitis}

American College of Chest Physicians-American College of Physicians/American Society of Internal Medicine Guidelines [13]

Mild exacerbation: presence of any one of the cardinal symptoms of increased dyspnea, increased sputum volume, or increased sputum purulence with the addition of an upper respiratory infection within the past 5 days, fever with no other cause, increased wheezing or cough, or a $20 \%$ rise over baseline in respiratory rate or heart rate.

Moderate exacerbation: presence of any two of the three cardinal symptoms of an exacerbation.

Severe exacerbation: presence of all three of the cardinal symptoms of an exacerbation.

International Consensus Group [15]

Mild exacerbation: patient has an increased need for medicaiton, which can be managed in the patient's normal environment.

Moderate exacerbation: patient has an increased need for medication and feels the need to seek additional medical assistance.

Severe exacerbation: patient/caregiver recognizes obvious and/ or rapid deterioration in condition, requiring hospitalization.

alveolar lavage samples, and tissue biopsied from the lung during exacerbations demonstrate the presence of inflammation within and surrounding airways [17-19]. During an acute exacerbation, this inflammation assumes characteristics of an allergic response increased eosinophils and upregulation of RANTES (regulated upon activation, normal T-cell expressed and secreted) in the epithelium and subepithelium [20]. Common triggers for acute exacerbations of COPD include airway infections [21], particulate air pollution [22], and environmental temperature changes [23], although up to $30 \%$ of patients have no clinically apparent etiologic factor [24]. Patients with acute exacerbations commonly have associated conditions such as congestive heart failure, pulmonary emboli, and extrapulmonary infections.

Bronchial infections are important causes of acute exacerbations with bacterial, atypical bacterial, and viral pathogens being the most commonly identified microbes (Box 2) [25]. Although the lower airway of patients with COPD harbors a mixed flora of bacteria, airway inflammation and bacterial load increases during an acute exacerbation $[25,26]$ These observations suggest that new or more virulent bacterial strains introduced into the airway population of colonized bacteria promote an inflammatory response that triggers acute exacerbations of 


\section{Box 2. Common infectious causes of acute exacerbations of chronic bronchitis}

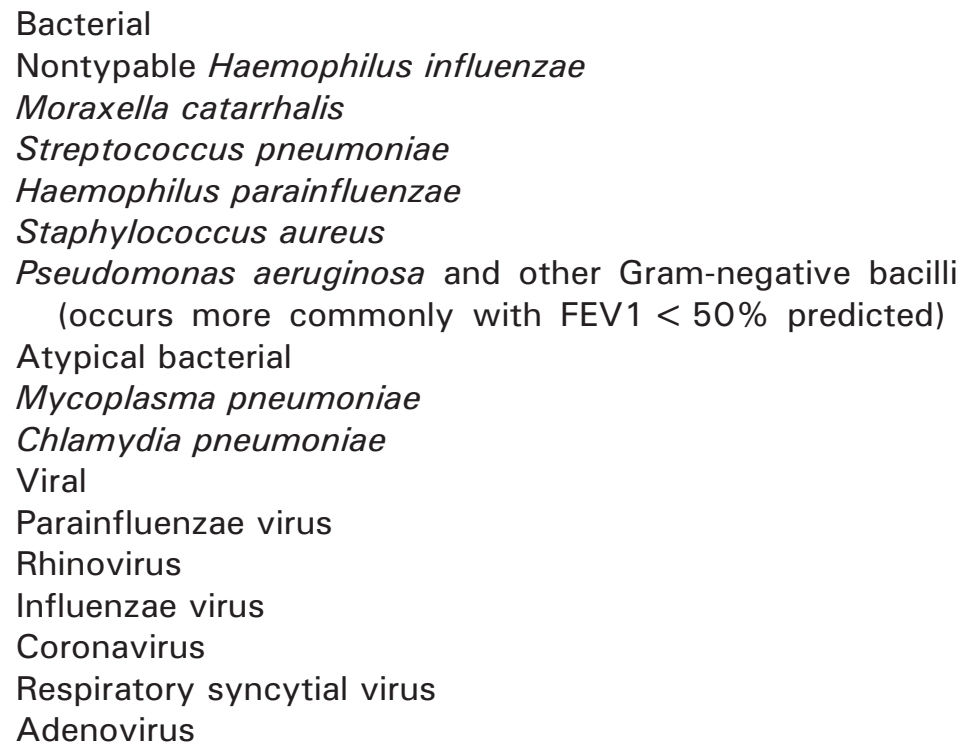

COPD [25]. Ten to $20 \%$ of patients with acute exacerbations have infections with two or more pathogens.

Among atypical pathogens, Chlamydia pneumoniae has been estimated to account for $5 \%$ to $10 \%$ of acute exacerbations but up to $18 \%$ of exacerbations that result in admission to the ICU [27,28]. Viral bronchitis is found in $30 \%$ to $40 \%$ of patients with acute exacerbations but only $16 \%$ of those who require ICU admission [28-30]. One recent study indicates that exacerbations due to viral bronchitis are more severe compared with nonviral exacerbations, and are associated with a longer time to recovery [30]. Viral particles have also been shown to produce latent infections, which can augment the inflammatory response to a subsequent stimulant of airway reactivity [31].

\section{Pharmacologic management of acute exacerbation of airway}

Elderly patients with an acute exacerbation of airway disease experience increased resistance to expiratory airflow and increased work of breathing, which can cause respiratory muscle fatigue. As shown by the spirometric flow-volume loops in Fig. 1, normal individuals breathe at rest with expiratory air flows that are well within the limits of their maximal flow rate capacity. Healthy persons, therefore, do not reach their maximal flow rates even with vigorous exercise. In contrast, patients with moderate to severe COPD have tidal volume flow rates 
A
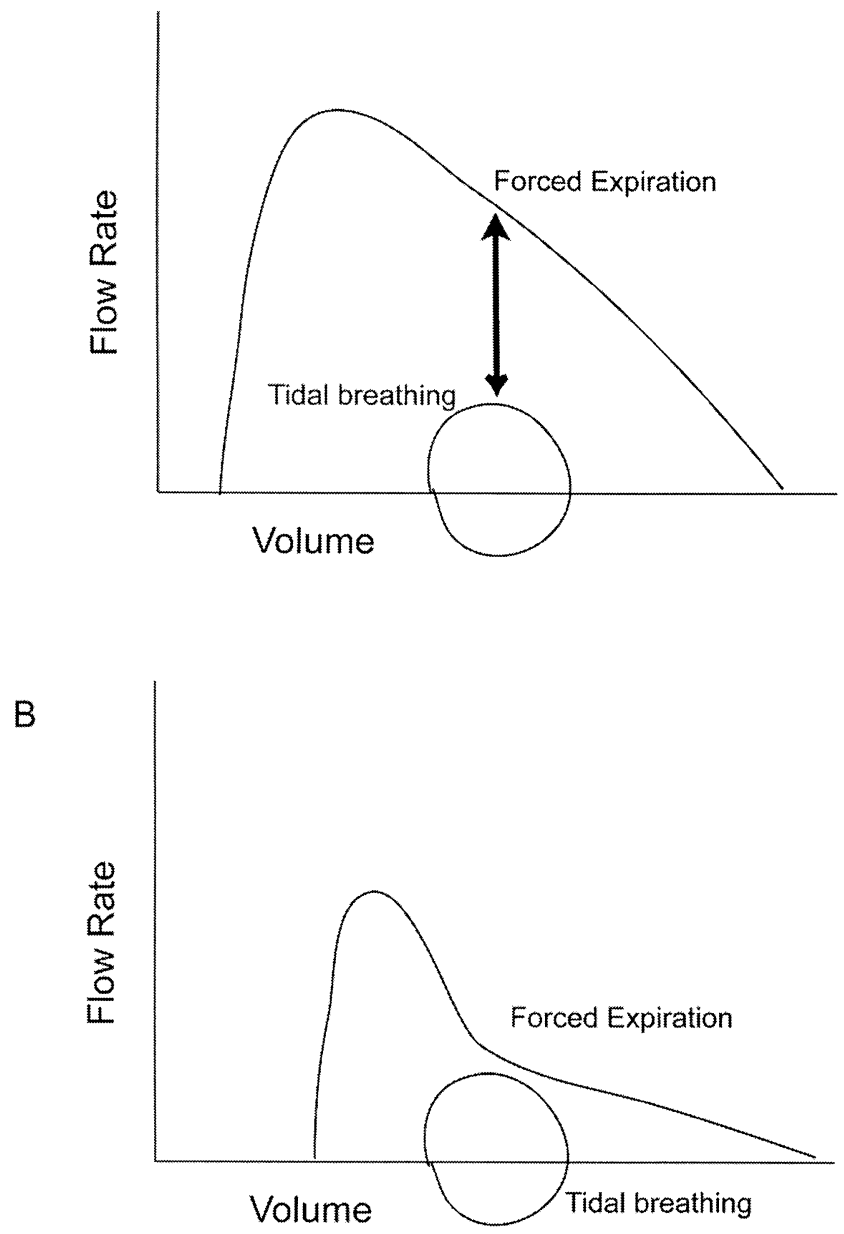

Fig. 1. Expiratory flow-volume loops with forced expiration and tidal breathing performed by a person with normal lungs $(A)$ and a person with severe COPD $(B)$. A person with normal lungs can markedly increase expiratory flow at lung volumes where tidal breathing occurs (double arrowhead line) in contrast to patients with COPD.

that are at or near their maximal flow rate capacity [32]. During an acute exacerbation, patients' attempts to increase minute ventilation by increasing tidal volume are limited by the low maximal flow rates. Patients respond with an increased respiratory rate, which decreases the time available for expiratory emptying of alveoli through narrowed airways. Patients experience progressive trapping of air within the lung ("dynamic hyperinflation"), which increases work of breathing [33]. Eventually, increasing fatigue prevents patients from meeting their ventilatory demands and causes hypercapnic respiratory failure [34]. Based on this pathophysiology of respiratory failure in COPD, management centers on decreasing 
airway resistance and decreasing work of breathing by "unloading" ventilatory demands on respiratory muscles to treat or prevent respiratory muscle fatigue.

Most therapeutic recommendations for managing elderly patients in the ICU with acute exacerbations of COPD derive from expert consensus because of the paucity of large prospective randomized trials [13]. Initial management includes supplemental oxygen by nasal cannulae or through a face mask that controls oxygen flow. Oxygen flows are titrated with goals of achieving oxygen saturation between $90 \%$ and $92 \%$ and a partial pressure of arterial oxygen between 60 to $64 \mathrm{~mm} \mathrm{Hg}$. Oxygen flow is monitored to prevent hypercapnia, which can result from the effects of supplemental oxygen on increasing dead-space ventilation and ventilation-perfusion mismatching.

Inhaled bronchodilators promote bronchodilation that can achieve a $15 \%$ to $29 \%$ increase in $\mathrm{FEV}_{1}$ and FVC within 1 to 2 hours [35]. Fourteen randomized trials support the conclusion that short-acting $\beta$-agonists (albuterol, levalbuterol, pirbuterol, bitolterol, fenoterol, metaproterenol, terbutaline) and anticholinergictype inhaled bronchodilators (ipratropium bromide) have similar efficacy for managing acute exacerbations, and both are more effective than parenteral bronchodilators [13]. The faster onset of action of $\beta$-agonists and the lower frequency of adverse effects with anticholinergic drugs determine drug selection for individual patients. No differences exist between the administration of inhaled bronchodilators by meter dose inhalers with a spacer or a jet nebulizer [36]. Initial therapy is usually started with a nebulizer, however, because critically ill patients with acute respiratory distress may experience difficulties using meter dose inhalers [35]. Patients are switched to metered dose inhaler (MDI) therapy as soon as they regain an ability to synchronize their breathing with the MDI device.

Although clinicians often combine inhaled short-acting $\beta$-agonists with ipratropium bromide for patients with acute exacerbations, existing data demonstrate only marginal benefits with combined therapy. The recent evidence-based consensus statement by the American College of Chest Physicians and the American College of Physicians/American Society of Internal Medicine recommends initial treatment with ipratropium bromide with the addition of a shortacting $\beta$-adrenergic agonist if patients do not respond to a maximal dose of the anticholinergic drug [13]. Other experts recommend the reverse approach beginning with a $\beta$-agonist drug [37]. The ideal dosing schedule for short-acting $\beta$-agonists and ipratropium bromide has not been established. High doses of $\beta$-agonists may cause tachyarrythmias, tremor, idiosyncratic bronchoconstriction, and tachyphylaxis [38,39].

Data do not support the use of parenteral aminophylline for critically ill elderly patients hospitalized in the ICU with acute exacerbations of COPD. In emergency department settings, short-term use of aminophylline demonstrates either no change in measurable outcomes [40] or a decreased risk of subsequent hospitalization [41]. The high rates of adverse effects in patients treated with aminophylline combined with its questionable benefit have markedly decreased the use of this drug in the ICU. Recent guidelines do not recommend the use of aminophylline for acute exacerbations of COPD [13]. 
The role of bacterial infections in causing exacerbations of airway disease support the use of antibiotics, although no studies have been performed in critically ill patients [13]. Cumulative findings from several studies, however, demonstrate benefit for patients with acute exacerbations who have severe exacerbations as marked by the presence of purulent sputum $[14,42,43]$. Because most studies of antibiotic efficacy for acute exacerbations were performed before the era of multidrug resistant bacteria, the appropriate selection of antibiotics for critically ill patients remains unclear. "First-line" antibiotics (doxycycline, trimethoprimsulfamethoxazole, amoxacillin) have been recommended for general ambulatory patients with acute exacerbations [35]. Many clinicians, however, use newer classes of more broad-spectrum antibiotics for hospitalized patients. Demonstration of superiority of these newer drugs awaits randomized controlled trials.

Pending the results of these studies, it is reasonable to recommend newer macrolides (azithromycin or clarithromycin), newer cephalosporins (cefpodoxime, cefprozil), amoxicillin/clavulanate, or doxycycline for hospitalized patients. Critically ill patients and patients with risk factors for poor outcomes (baseline $\mathrm{FEV}_{1}<50 \%$ predicted, comorbid conditions, three or more exacerbations during the last 12 months) benefit from newer fluoroquinolones (levofloxacin, gatifloxacin, moxifloxacin) because of the risk of Gram-negative organisms. If Pseudomonas aeruginosa is suspected (baseline $\mathrm{FEV}_{1}<35 \%$ predicted, underlying bronchiectasis, multiple courses of antibiotics), ciprofloxacin is the preferred antibiotic [44].

Prospective, randomized controlled trials demonstrate that systemic corticosteroids improve outcome for patients with acute exacerbations, as demonstrated by more rapid improvement in measured airflow, gas exchange, and respiratory symptoms with decreased treatment failure rates and relapse rates [13]. Existing studies have used different treatment regimens so the optimal dose and duration of corticosteroids are unknown. The largest study to date of hospitalized patients, however, used methylprednisolone, $125 \mathrm{mg}$ IV every 6 hours for 3 days followed by a corticosteroid tapering schedule using oral prednisone [45]. Patients treated for 2 weeks with corticosteroids did as well as patients treated for 8 weeks. Hyperglycemia is the major complication of corticosteroid therapy for hospitalized patients with acute exacerbations [45].

No studies support the use of expectorants, mucolytic agents, or mucokinetic drugs in managing critically ill patients with COPD [13]. Physical therapy with postural drainage and chest clappage may acutely worsen respiratory function without providing any measurable benefit.

\section{Ventilatory support for patients with acute exacerbation}

Positive pressure ventilation unloads respiratory muscles and prevents or treats respiratory muscle fatigue. Ventilatory support can be provided by a tight-fitting face mask in the form of noninvasive positive pressure ventilation (NIPPV) or by tracheal intubation with mechanical ventilation. 
NIPPV has been shown in randomized controlled trials to provide benefits to subsets of patients with acute respiratory failure by decreasing the need for intubation, shortening hospital stay, and increasing survival [46-49]. Many of these benefits occur because of the lower risk for pneumonia with NIPPV compared with intubation and mechanical ventilation [50]. The rationale for NIPPV derives from the respiratory muscle unloading that occurs during ventilatory support that allows patients to maintain adequate breathing until the underlying airway problems reverse [49].

All hospitalized elderly patients who present with respiratory distress from acute exacerbations should be evaluated for NIPPV. Patients admitted with even mild respiratory acidosis may benefit from NIPPV [51]. Unfortunately, only $20 \%$ of hospitalized patients are candidates for NIPPV [52]. Poor candidates for NIPPV include patients with cardiovascular instability, respiratory arrest, limited ability to clear increased airway secretions, poor airway control, agitation or severe encephalopathy (Glascow Coma Scale < 10), uncooperability, upper gastrointestinal bleeding, upper airway obstruction, high risk for aspiration, and facial features that interfere with proper fitting of a face mask [35]. Recent studies demonstrate that the use of NIPPV does not require more nursing or respiratory therapist time compared with intubation and mechanical ventilation [49]. Basic principles for initiating NIPPV are listed in (Box 3). The key to successful application of NIPPV for patients with COPD is thoughtful individualization of care and cautious titration of the positive pressure support.

Patients with severe respiratory failure who are not candidates for NIPPV require intubation and mechanical ventilation. Ventilatory support provides an increased minute ventilation to correct abnormalities in gas exchange, and unloads respiratory muscles to allow recovery from respiratory muscle fatigue.

\section{Box 3. Principles for initiating noninvasive positive pressure ventilation}

Identify appropriate patient

Review the equipment with the patient and explain care

Fit an appropriate-sized mask

Adjust ventilator initially at a low pressure $\left(8-10 \mathrm{~cm} \mathrm{H} \mathrm{H}_{2} \mathrm{O}\right.$ inspiration; $4-5 \mathrm{~cm} \mathrm{H} \mathrm{H}_{2} \mathrm{O}$ expiration) with the patient holding the mask in place.

Ask the patient to report comfort level and adjust ventilator pressures accordingly

Adjust oxygen flow rates to meet target oxygen saturation levels

Adjust the mask to avoid leaks

Monitor patient frequently and coach breathing patterns

Gradually increase inspiratory pressures for maximal relief of dyspnea 
Although the specific techniques of mechanical ventilation are beyond the scope of the present article, general principles center on the avoidance of dynamic hyperinflation. Patients with acute respiratory failure have increased airflow limitation, which slows expiratory airflow and delays alveolar empyting. Mechanical ventilation with large tidal volumes and rapid respiratory rates produce dynamic hyperinflation and raised alveolar pressures at end expiration, which is termed autopositive end expiratory pressure (auto-PEEP). Auto-PEEP interferes with patients' abilities to spontaneously trigger the ventilator, creates discomfort that may require heavy sedation, and compromises cardiac function. Strategies to avoid dynamic hyperinflation include use of lower tidal volumes, increased inspiratory flow rates, and moderate respiratory rates. Use of applied-PEEP at a lower level than measured auto-PEEP may enhance ventilator triggering and promote patient comfort. More detailed reviews of ventilator strategies for patients with COPD are reviewed elsewhere [53].

\section{Weaning from mechanical ventilation}

Most patients intubated for respiratory failure due to COPD improve within the first 72 hours of care and undergo successful weaning and early extubation. Goals for these patients are to reverse bronchospasm, rest fatigued ventilatory muscles, prevent dynamic hyperinflation, and avoid oversedation, which is associated with increased risks for nosocomial pneumonia and delayed weaning. Patients who require mechanical ventilation for longer than 72 hours are at increased risk of death and long-term mechanical ventilation [54].

Although no prospective, randomized data support the role of early tracheotomy for ventilator-dependent patients with COPD [55], we have found tracheotomy valuable in promoting patient comfort with decreased need for analgesics and sedatives, improved nutrition, articulated speech, and patient mobility [56]. These factors combined with the improved access to the lower airways for pulmonary toilet and decreased airway resistance during weaning trials promote successful weaning. We evaluate patients for tracheotomy after 7 days of intubation. If successful extubation appears unlikely during the next several days, we proceed to tracheotomy to promote patient comfort and an early weaning from ventilatory support [57].

\section{Prognosis and outcome}

COPD is a progressive disease characterized by a long preclinical phase and a gradual decline in lung function over years after patients become symptomatic. Some patients experience an abrupt and permanent loss of lung function during acute exacerbations. It is not possible to predict the clinical course of individual patients with COPD because of the variability of the disease and limitations of studies that examine clinical predictors. Studies have observed, however, 
accelerated decline in lung function in heavy and current smokers and in patients with mucus hypersecretion, low functional status, airway hyperreactivity, polymorphism in the TNF- $\alpha$ gene promoter region, and elevated levels of fibrinogen [58-62].

The prognosis for patients hospitalized with an acute exacerbation associated with hypercapnia is poor in terms of survival and postdischarge health-related quality of life. Prognosis is determined more by the severity of the underlying COPD than by factors associated with the hospitalization. More than $50 \%$ of patients admitted with an acute exacerbation require rehospitalization within 6 months $[63,64]$. The mortality of patients hospitalized for an acute exacerbation is $3 \%$ to $4 \%$ [65], but mortality climbs to $11 \%$ to $24 \%$ for patients who require ICU admission [63,66]. The 60-day, 180-day, 1-year, and 2-year mortality for patients discharged after an acute exacerbation is $20 \%, 33 \%, 43 \%$, and $49 \%$, respectively $[63,67]$. Six months after discharge, only $26 \%$ of patients are alive and able to report a good, very good, or excellent quality of life [63]. Disabling symptoms of dyspnea are the most important factors decreasing quality of life [67].

In view of this poor long-term prognosis both in terms of survival and quality of life, risk stratification models to identify patients at high risk of inpatient death or a poor postdischarge outcome would assist patient selection for intubation. Niewoehner et al observed that the $\mathrm{FEV}_{1}$ at admission and over the first several days of hospitalization is highly associated with clinical outcome [68]. For patients who require intubation and mechanical ventilation, comorbidities, and acute illness severity scores are predictive of survival [54]. Requirements for mechanical ventilation beyond 72 hours and extubation followed by reintubation are associated with a high mortality [54]. Connors et al reported data from The Study to Understand Prognoses and Preferences for Outcomes and Risks of Treatments that found an independent association of severity of illness scores, body mass index, older age, prior functional status, severity of hypoxia, congestive heart failure, serum albumin, and the presence of cor pulmonale with survival [63]. Almagro et al [69] recently reported that quality of life, marital status, depressive symptoms, comorbidity, and prior hospital admission identified hospitalized patients with a poor postdischarge survival [69].

Unfortunately, none of these models successfully identifies individual patients who have greater than $90 \%$ likelihood of dying [13]. Moreover, most of these prediction models have not been validated in an independent cohort. Consequently, no existing system for predicting inpatient mortality or postdischarge functional capacity is suitable for selecting patients for instituting, continuing, or withdrawing life-sustaining therapies [70,71].

\section{Palliative and end-of-life care in the ICU}

Most patients with advanced COPD want to make their own decisions regarding life-supportive care either by communicating with their physicians 
directly or through an appointed surrogate or instrument of advance care planning [72]. To make informed decisions, however, patients need to understand the nature of life-supportive interventions and the probability of different outcomes if life interventions are used for respiratory failure. Unfortunately, most elderly patients with moderate to severe COPD have not discussed with their primary care physicians the appropriateness of life-supportive care or the nature of intubation and mechanical ventilation [72].

If advance care planning has not occurred in the outpatient setting, discussions regarding the appropriateness of life-sustaining care should take place during the hospitalization for an acute exacerbation. Ideally, the primary physician who knows the patient most intimately should initiate these discussions, which has been termed "captaincy" [73]. Often, however, the primary care physician is not available to discuss end-of-life care during hospitalization in the ICU, which requires the critical care physician to serve this role.

In discussing end-of-life care, critical care physicians need to inform patients and families about the anticipated value of life-supportive care. They should adopt, however, a broader approach to advance care planning that incorporates the patient's perspective. Physicians in the ICU often over focus on discussions regarding the life-sustaining interventions that should be applied in various clinical circumstances. Patients and families, however, have more overarching goals that pertain to preparing for death, achieving a sense of control, and securing personal relationships with friends and families. Patients with terminal COPD are oriented toward their psychologic, emotional, and spiritual needs. Discussions may shift from patient-physician discussions on the use of lifesupportive interventions to patient-family-friend communications to fortify relationships and share decisions about life-supportive care through mutual support [74].

Patients with acute exacerbations who choose to forego life-supportive care or have it withdrawn need relief of pain and suffering and expert management of their end-of-life care [75]. They also benefit from reassurance that their physicians and nurses will not back away from their care. Disabling symptoms of cough, dyspnea, anxiety, and depression typically complicate the terminal course of patients dying with COPD [75]. Most patients at the terminal stage of COPD choose not to use ventilator support, or to use it only for a time-limited span, if they can be sure of competent relief of terrifying dyspnea.

\section{Summary}

COPD is a progressive disorder that is punctuated in its later stages with acute exacerbations that present a risk for respiratory failure. COPD has a disproportionate impact on older patients. In the ICU, therapy is directed toward unloading fatigued respiratory muscles, treating airway infection, and prescribing bronchodilatory drugs. Most patients survive hospitalization in the ICU for an episode of respiratory failure. The severity of the underlying lung disease, however, under- 
lies the poor outcomes of patients in terms of postdischarge survival and quality of life.

\section{References}

[1] National Center for Health Statistics. Report of final morbidity statistics. Hyattsville, MD: NCHS; 1998.

[2] Hurd S. The impact of COPD on lung health worldwide: epidemiology and incidence. Chest 2000;117:1S-4S.

[3] Mannino DM. COPD: epidemiology, prevalence, morbidity and mortality, and disease heterogeneity. Chest 2002;121:121S-6S.

[4] Centers for Disease Control and Prevention. Mortality patterns: preliminary data: United States1996. Morb Mortal Wkly Rep 1997;46:941-4.

[5] Wilson L, Devine EB, So K. Direct medical costs of chronic obstructive pulmonary disease: chronic bronchitis and emphysema [in process citation]. Respir Med 2000;94:204-13.

[6] Murray CLJ, Lopez A. Evidence-based health policy: lessons from the global burden of diseases study. Science 1996;274:740-3.

[7] World Health Organization. World health report 1997: full report; world health 1999. Geneva: World Health Organization; 2000.

[8] Grasso ME, Weller WE, Shaffer TJ, et al. Capitation, managed care, and chronic obstructive pulmonary disease. Am J Respir Crit Care Med 1998;158:133-8.

[9] Strassels SA, Smith DH, Sullivan SD, Mahajan PS. The costs of treating COPD in the United States. Chest 2001;119:344-52.

[10] Stang P, Lydick E, Silberman C, Kempel A, Keating ET. The prevalence of COPD: using smoking rates to estimate disease frequency in the general population. Chest 2000;117:354S-9S.

[11] Zielinski J, Bednarek M. Early detection of COPD in a high-risk population using spirometric screening. Chest 2001;119:731-6.

[12] Feenstra TL, van Genugten ML, Hoogenveen RT, Wouters EF, Rutten-van Molken MP. The Impact of aging and smoking on the future burden of chronic obstructive pulmonary disease. A model analysis in the netherlands. Am J Respir Crit Care Med 2001;164:590-6.

[13] Snow V, Lascher S, Mottur-Pilson C. The evidence base for management of acute exacerbations of COPD: clinical practice guideline, part 1. Chest 2001;119:1185-9.

[14] Anthonisen NR, Manfreda J, Warren CP, et al. Antibiotic therapy in exacerbations of chronic obstructive pulmonary disease. Ann Intern Med 1987;106:196-204.

[15] Rodriguez-Roisin R. Toward a consensus definition for COPD exacerbations. Chest 2000;117: 398S-401S.

[16] Seemungal TA, Donaldson GC, Bhowmik A, Jeffries DJ, Wedzicha JA. Time course and recovery of exacerbations in patients with chronic obstructive pulmonary disease. Am J Respir Crit Care Med 2000;161:1608-13.

[17] Bhowmik A, Seemungal TA, Sapsford RJ, Wedzicha JA. Relation of sputum inflammatory markers to symptoms and lung function changes in COPD exacerbations. Thorax 2000;55: $114-20$.

[18] Saetta M, Di Stefano A, Maestrelli P, Turato G, Ruggieri MP, Roggeri A, et al. Airway eosinophilia in chronic bronchitis during exacerbations. Am J Respir Crit Care Med 1994;150:1646-52.

[19] Saetta M, Di Stefano A, Maestrelli P, Turato G, Mapp CE, Pieno M, et al. Airway eosinophilia and expression of interleukin-5 protein in asthma and in exacerbations of chronic bronchitis. Clin Exp Allergy 1996;26:766-74.

[20] Zhu J, Qiu YS, Majumdar S, Gamble E, Matin D, Turato G, et al. Exacerbations of Bronchitis: bronchial eosinophilia and gene expression for interleukin-4, interleukin-5, and eosinophil chemoattractants. Am J Respir Crit Care Med 2001;164:109-16.

[21] Stockley RA, O'Brien C, Pye A, Hill SL. Relationship of sputum color to nature and outpatient management of acute exacerbations of COPD. Chest 2000;117:1638-45. 
[22] Anderson HR, Spix C, Medina S, Schouten JP, Castellsague J, Rossi G, et al. Air pollution and daily admissions for chronic obstructive pulmonary disease in 6 European cities: results from the APHEA project. Eur Respir J 1997;10:1064-71.

[23] Donaldson GC, Seemungal T, Jeffries DJ, Wedzicha JA. Effect of temperature on lung function and symptoms in chronic obstructive pulmonary disease. Eur Respir J 1999;13:844-9.

[24] Chodosh S, McCarty J, Farkas S, Drehobl M, Tosiello R, Shan M, et al. Randomized, doubleblind study of ciprofloxacin and cefuroxime axetil for treatment of acute bacterial exacerbations of chronic bronchitis. The Bronchitis Study Group. Clin Infect Dis 1998;27:722-9.

[25] Sethi S. Infectious etiology of acute exacerbations of chronic bronchitis. Chest 2000;117: $380 \mathrm{~S}-5 \mathrm{~S}$.

[26] Yi K, Sethi S, Murphy TF. Human immune response to nontypeable Haemophilus influenzae in chronic bronchitis. J Infect Dis 1997;176:1247-52.

[27] Blasi F, Legnani D, Lombado VM, et al. Chlamydia pneumoniae infection in acute exacerbations of COPD. Eur Respir J 1993;6:19-22.

[28] Soler N, Torres A, Ewig S, Gonzalez J, Celis R, El-Ebiary M, et al. Bronchial microbial patterns in severe exacerbations of chronic obstructive pulmonary disease (COPD) requiring mechanical ventilation. Am J Respir Crit Care Med 1998;157:1498-505.

[29] Gump DW, Phillips CA, Forsyth BR, McIntosh K, Lamborn KR, Stouch WH. Role of infection in chronic bronchitis. Am Rev Respir Dis 1976;113:465-74.

[30] Seemungal T, Harper-Owen R, Bhowmik A, Moric I, Sanderson G, Message S, et al. Respiratory viruses, symptoms, and inflammatory markers in acute exacerbations and stable chronic obstructive pulmonary disease. Am J Respir Crit Care Med 2001;164:1618-23.

[31] Matsuse T, Hayashi S, Kuwano K, Keunecke H, Jefferies WA, Hogg JC. Latent adenoviral infection in the pathogenesis of chronic airways obstruction. Am Rev Respir Dis 1992;146: $177-84$.

[32] O'Donnell DE, Revill SM, Webb KA. Dynamic hyperinflation and exercise intolerance in chronic obstructive pulmonary disease. Am J Respir Crit Care Med 2001;164:770-7.

[33] Hyatt RE. Expiratory flow limitation. J Appl Physiol 1983;55:1-7.

[34] O'Donnell SE, Sanil R, Anthonisen NR, et al. Effect of dynamic airway compression on breathing pattern and respiratory sensation in severe chronic obstructive pulmonary disease. Am Rev Respir Dis 1987;135:912-8.

[35] Stoller JK. Clinical practice. Acute exacerbations of chronic obstructive pulmonary disease. N Engl J Med 2002;346:988-94.

[36] Turner JR, Corkery KJ, Eckman D, et al. Equivalence of continuous flow nebulizer and metered dose inhaler with reservoir bag for treatment of acute airflow obstruction. Chest 1988;93:476-81.

[37] Pauwels RA, Buist AS, Calverley PM, Jenkins CR, Hurd SS. Global strategy for the diagnosis, management, and prevention of chronic obstructive pulmonary disease. NHLBI/WHO Global Initiative for Chronic Obstructive Lung Disease (GOLD) Workshop summary. Am J Respir Crit Care Med 2001;163:1256-76.

[38] Tashkin DP, Ashutosh K, Bleecker ER, Britt EJ, Cugell DW, Cummiskey JM, et al. Comparison of the anticholinergic bronchodilator ipratropium bromide with metaproterenol in chronic obstructive pulmonary disease. A 90-day multi-center study. Am J Med 1986;81:81-90.

[39] Au DH, Lemaitre RN, Curtis JR, Smith NL, Psaty BM. The risk of myocardial infarction associated with inhaled beta-adrenoceptor agonists. Am J Respir Crit Care Med 2000;161: $827-30$.

[40] Rice KL, Leatherman JW, Duane PG, Snyder LS, Harmon KR, Abel J, et al. Aminophylline for acute exacerbations of chronic obstructive pulmonary disease. A controlled trial. Ann Intern Med 1987;107:305-9.

[41] Wrenn K, Slovis CM, Murphy F, Greenberg RS. Aminophylline therapy for acute bronchospastic disease in the emergency room. Ann Intern Med 1991;115:241-7.

[42] Saint S, Bent S, Vittinghoff E, Grady D. Antibiotics in chronic obstructive pulmonary disease exacerbations. A meta-analysis. JAMA 1995;273:957-60. 
[43] McCrory DC, Brown C, Gelfand SE, Bach PB. Management of acute exacerbations of COPD: a summary and appraisal of published evidence. Chest 2001;119:1190-209.

[44] Miravitlles M, Espinosa C, Fernandez-Laso E, Martos JA, Maldonado JA, Gallego M. Relationship between flora in sputum and functional impairment in patients with acute exacerbations of COPD. Study Group of Bacterial Infection in COPD. Chest 1999;116:40-6.

[45] Niewoehner DE, Erbland ML, Deupree RH, Collins D, Gross NJ, Light RW, et al. Effect of systemic glucocorticoids on exacerbations of chronic obstructive pulmonary disease. Department of Veterans Affairs Cooperative Study Group. N Engl J Med 1999;340:1941-7.

[46] Angus RM, Ahmed AA, Fenwick LJ, Peacock AJ. Comparison of the acute effects on gas exchange of nasal ventilation and doxapram in exacerbations of chronic obstructive pulmonary disease. Thorax 1996;51:1048-50.

[47] Brochard L, Mancebo J, Wysocki M, et al. Noninvasive ventilation for acute exacerbations of chronic obstructive pulmonary disease. N Engl J Med 1995;333:817-22.

[48] Kramer N, Meyer TJ, Meharg J, et al. Randomized, prospective trial of noninvasive positive pressure ventilation in acute respiratory failure. Am J Respir Crit Care Med 1995;151:1799-806.

[49] International Consensus Conferences in Intensive Care Medicine. Noninvasive positive pressure ventilation in acute Respiratory failure. Am J Respir Crit Care Med 2001;163:283-91.

[50] Keenan SP, Gregor J, Sibbald WJ, Cook D, Gafni A. Noninvasive positive pressure ventilation in the setting of severe, acute exacerbations of chronic obstructive pulmonary disease: more effective and less expensive. Crit Care Med 2000;28:2094-102.

[51] Plant PK, Owen JL, Elliott MW. Early use of non-invasive ventilation for acute exacerbations of chronic obstructive pulmonary disease on general respiratory wards: a multicentre randomised controlled trial. Lancet 2000;355:1931-5.

[52] Plant PK, Owen JL, Elliott MW. One year period prevalence study of respiratory acidosis in acute exacerbations of COPD: implications for the provision of non-invasive ventilation and oxygen administration. Thorax 2000;55:550-4.

[53] Sethi JM, Siegel MD. Mechanical ventilation in chronic obstructive lung disease. Clin Chest Med 2000;21:799-818.

[54] Nevins ML, Epstein SK. Predictors of outcome for patients with COPD requiring invasive mechanical ventilation. Chest 2001;119:1840-9.

[55] Heffner JE. The role of tracheotomy in weaning. Chest 2001;120:477S-81S.

[56] Heffner JE, Hess D. Tracheostomy management in the chronically ventilated patient. Clin Chest Med 2001;22:55-69.

[57] Heffner JE. Timing of tracheotomy in mechanically ventilated patients. Am Rev Respir Dis 1993; 147:768-71.

[58] Anthonisen NR, Connett JE, Kiley JP, Altose MD, Bailey WC, Buist AS, et al. Effects of smoking intervention and the use of an inhaled anticholinergic bronchodilator on the rate of decline of FEV1. The Lung Health Study. JAMA 1994;272:1497-505.

[59] Tashkin DP, Altose MD, Connett JE, Kanner RE, Lee WW, Wise RA. Methacholine reactivity predicts changes in lung function over time in smokers with early chronic obstructive pulmonary disease. The Lung Health Study Research Group. Am J Respir Crit Care Med 1996;153:1802-11.

[60] Vestbo J, Prescott E, Lange P. Association of chronic mucus hypersecretion with FEV1 decline and chronic obstructive pulmonary disease morbidity. Copenhagen City Heart Study Group. Am J Respir Crit Care Med 1996;153:1530-5.

[61] Prescott E, Lange P, Vestbo J. Chronic mucus hypersecretion in COPD and death from pulmonary infection. Eur Respir J 1995;8:1333-8.

[62] Bowen JB, Votto JJ, Thrall RS, Haggerty MC, Stockdale-Woolley R, Bandyopadhyay T, et al. Functional status and survival following pulmonary rehabilitation. Chest 2000;118:697-703.

[63] Connors AFJ, Dawson NV, Thomas C, et al. Outcomes following acute exacerbation of severe chronic obstructive lung disease. J Respir Crit Care Med 1996;154:959-67.

[64] Weinberger M, Oddone EZ, Henderson WG. Does increased access to primary care reduce hospital readmissions? Veterans Affairs Cooperative Study Group on Primary Care and Hospital Readmission. N Engl J Med 1996;334:1441-7. 
[65] Mushlin AI, Black ER, Connolly CA, et al. The necessary length of hospital stay for chronic pulmonary disease. JAMA 1991;266:80-3.

[66] Claessens MT, Lynn J, Zhong Z, Desbiens NA, Phillips RS, Wu AW, et al. Dying with lung cancer or chronic obstructive pulmonary disease: insights from SUPPORT. Study to understand prognoses and preferences for outcomes and risks of treatments. J Am Geriatr Soc 2000;48: S146-53.

[67] Lynn J, Ely EW, Zhong Z, McNiff KL, Dawson NV, Connors A, et al. Living and dying with chronic obstructive pulmonary disease. J Am Geriatr Soc 2000;48:S91-100.

[68] Niewoehner DE, Collins D, Erbland ML. Relation of FEV(1) to clinical outcomes during exacerbations of chronic obstructive pulmonary disease. Department of Veterans Affairs Cooperative Study Group. Am J Respir Crit Care Med 2000;161:1201-5.

[69] Almagro P, Calbo E, Ochoa de Echaguen A, Barreiro B, Quintana S, Heredia JL, et al. Mortality after hospitalization for COPD. Chest 2002;121:1441-8.

[70] Fox E, Landrum-McNiff K, Zhong Z, Dawson NV, Wu AW, Lynn J. Evaluation of prognostic criteria for determining hospice eligibility in patients with advanced lung, heart, or liver disease. SUPPORT Investigators. Study to understand prognoses and preferences for outcomes and risks of treatments [see comments]. JAMA 1999;282:1638-45.

[71] Heffner JE. Chronic obstructive pulmonary disease - ethical considerations of care. Clin Pulm Med 1996;3:1-8.

[72] Heffner JE, Fahy B, Hilling L, Barbieri C. Attitudes regarding advance directives among patients in pulmonary rehabilitation. Am J Respir Crit Care Med 1996;154:1735-40.

[73] Miles SH, Koepp R, Weber EP. Advance end-of-life treatment planning. A research review. Arch Intern Med 1996;156:1062-8.

[74] Papa-Kanaan JM, Sicilian L. Ethical issues in the chronically critically ill patient. Clin Chest Med 2001;22:209-17.

[75] Hansen-Flaschen J. Advanced lung disease: palliation and terminal care. Clin Chest Med 1997; 18:645-55. 